\title{
Mulheres e jornalismo esportivo: possibilidades e limitações em um campo masculino
}

\author{
Leonardo Turchi Pacheco' (iD) 0000-0003-0390-1608 \\ Silvio Ricardo da Silva ${ }^{2}$ (i) 0000-0003-0584-3675 \\ Universidade Federal de Alfenas, Alfenas, MG, Brasil. \\ 37130-001-ichl@unifal-mg.edu.br \\ ${ }^{2}$ Universidade Federal de Minas Gerais, Belo Horizonte, MG, Brasil. \\ 31270-901-colgraded-fis@eeffto.ufmg.br
}

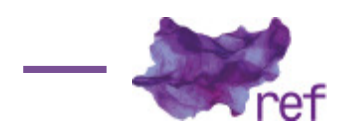

Resumo: Este artigo tem como objetivo abordar as possibilidades e limitações de inserção, permanência e sucesso de mulheres no jornalismo esportivo. A coleta de dados foi realizada através da metodologia qualitativa e está alicerçada nas técnicas de pesquisa observação participante e entrevistas semiestruturadas que foram realizadas com 38 jornalistas que trabalham ou trabalharam em Belo Horizonte. Este texto, fundamentado teoricamente em autores e autoras que se vinculam às perspectivas feministas em suas abordagens sobre esporte e mídia, evidencia o perfil, a trajetória profissional, os espaços ocupados, os constrangimentos e as estratégias utilizadas por essas mulheres para transitar nesse campo majoritariamente masculino.

Palavras-chave: mulheres; esporte; mídia.

Women and the Sports Journalism: Possibilities and Limitations in a Masculine Field Abstract: The aim of this article is to approach the possibilities and limitations women face to get access, remain, and succeed in the field of sports journalism. The research is based on a qualitative method and supported by a set of techniques such as participant observations and semi-structured interviews. The interviews were conducted with 38 female journalists that were working or had worked in the city of Belo Horizonte, Minas Gerais. Theoretically based on feminist's theories on sports and media, this text takes advantage of the analyses of authors and authoresses that combine those approaches. In doing so they highlight the profile of these women, their professional trajectory, the spaces allowed in, the constraints and embarrassments that they are submitted to and the strategies that they use to move through this major masculine field.

Key words: Women; Sports; Media.

\section{Introdução}

O jornalismo esportivo em Belo Horizonte é um campo de atividade profissional, nos termos concebidos por Pierre Bourdieu (1997) e Érik Neveu (2006) proeminentemente masculino. A assimetria entre o número de homens e mulheres trabalhando nessa especialidade do jornalismo, na capital mineira, pode ser percebida nos cadastros da Associação Mineira de Cronistas Esportivos (AMCE) no ano de 2016.

No início de 2016 estavam cadastrados na AMCE um total de 1.388 jornalistas: 1.343 homens e apenas 45 mulheres. Apesar desse desequilíbrio entre cadastrados e cadastradas, 0 impacto da surpresa se desfaz quando se observa os resultados de estudos que tratam das desigualdades de gênero no mercado de trabalho (Elisabeth S. LOBO, 1991; Cristina BRUSCHINI, 1994; Magda A. NEVES, 2013). Segundo essas autoras, a inserção da mulher no mercado de 
trabalho é marcada por discriminações que limitam o leque de oportunidades na escolha de uma profissão e de desenvolvimento de carreira dentro do local de trabalho. Essas dificuldades são suplementadas quando, além do gênero, a interseccionalidade classe e raça (Helena HIRATA, 2014; Danubia de A. FERNANDES, 2016; Sueli CARNEIRO, 2016) entram na equação para compreender as desigualdades no mercado de trabalho. Isso porque essas interseccionalidades apontam para uma superposição de desigualdades que excluem, em sua maioria, mulheres negras de camadas populares de ocupações formais na esfera pública.

Ademais, sabe-se que o esporte é uma área de reserva masculina. Como assinala Eric Dunning (2014), essa arena se constitui como um dos espaços legítimos de expressão da masculinidade hegemônica. As mulheres são sistematicamente excluídas, invisibilizadas e sofrem violência física e simbólica nesse campo. Esses processos ocorrem por meio de práticas e discursos que produzem e reproduzem crenças e comportamentos que favorecem as masculinidades consideradas como hegemônicas frente a outros atores que interagem nesse meio.

Por ser uma reserva de masculinidade, Bruce Kidd (1990) indica que os esportes são um campo fértil para a manutenção do poder masculino e de seus privilégios. Tomando como locus de observação as relações de gênero no esporte em Toronto, Canadá, esse autor aponta para constantes desencorajamentos que têm por objetivo a exclusão das mulheres na prática e fruição dos esportes.

Exclusão percebida em outros contextos e países como revelam os trabalhos de Nancy Theberge (1994), Jennifer Hargreaves (1994), Miriam Adelman (2003) e Silvana Goellner (2005). Essas autoras observam que as relações de desigualdade entre homens e mulheres no campo dos esportes são marcadas pela complexidade, contradição e controvérsia, uma vez que englobam desde proibições de participação de clubes esportivos, passando pela justificação biológica para a proibição de prática em determinadas modalidades, pela invisibilidade, discriminação e banalização das práticas esportivas femininas, até por políticas públicas que favorecem determinadas mulheres e excluem outras da prática esportiva, contribuindo dessa maneira para desigualdades percebidas como naturalmente dadas. Lois Bryson (1990) segue a mesma linha de raciocínio que os autores e autoras mencionados acima. Para a autora, a promoção da dominação masculina nessa esfera social estaria intimamente ligada ao prestígio dado pela associação entre violência, força física e poder.

Assim, os esportes promoveriam a masculinidade hegemônica pelo controle direto das corporações esportivas por homens, mesmo no caso das modalidades femininas, pela inferiorização do outro (mulheres e homossexuais) e pelo reconhecimento da violência como forma positiva e legítima de comportamentos e de expressão individualidade. Paul Willis (1994) complementa essa argumentação ao indicar que a trivialização das conquistas femininas, o humor depreciativo, baseado em estereótipos sobre a sexualidade, a corporeidade e o comportamento das praticantes contribuem para tornar as atletas desviantes e outsiders nessa esfera.

As condições de desigualdades e constrangimentos que acometem as mulheres atletas não são estranhas às experiências de jornalistas que trabalham cobrindo a área de esportes. E é nessa direção que apontam os estudos que abordam a presença de mulheres jornalistas em redações, emissoras de rádio e televisão no contexto brasileiro (Marcia V. da SILVA, 2010; Thais de M. JORGE; Zélia L. ADGHIRNI, 2013; Carmen RIAL, 2014; Roseli FIGARO, 2014; Adriana BRUM; André M. CAPRARO, 2015), no norte-americano (Pamela CREEDON, 1994b; THEBERGE; Alan CRONK, 1994; Phyllis MILLER; Randy MILLER, 1995; Deborah CHAMBERS; Linda STEINER; Carol FLEMMING, 2004) e no europeu (Liesbet VAN ZOONEN, 1998; Karen ROSS, 2001; Raymond BOYLE, 2006). Em todas essas abordagens há a identificação desses espaços - mesmo com o crescente número de mulheres adentrando a profissão, como demonstra Figaro (2014) ao revelar a feminilização da profissão a partir da década de 1990 - com uma cultura masculina (sexista e misógina) na qual persistem valores e privilégios masculinos em contraposição à submissão e subserviência feminina indicando a falsa representação de mulheres nessa esfera, como revelam os dados da pesquisa sobre gênero e mídia publicados pela Artigo 19 (2017).

Hargreaves (1994) e Garry Whannel (2006) reforçam que o jornalismo esportivo é controlado por homens quando evidenciam que os discursos, imagens e suas mensagens são direcionados, na sua maioria, para uma audiência masculina que é naturalmente pensada como públicoalvo. Além disso, essas relações vão além do nível de produção de discursos e imagens, pois se inserem na dinâmica do próprio campo do jornalismo esportivo, direcionando as mulheres para certas atividades e revelando impedimentos e entraves no exercício da profissão.

Partindo da premissa teórica de que o jornalismo esportivo é um espaço masculino, este artigo propõe uma reflexão sobre a dinâmica de gênero nesse espaço no contexto belo-horizontino, por meio de dados coletados em sete meses de pesquisa de campo' e 38 entrevistas semiestruturadas com as

\footnotetext{
' A coleta de dados foi realizada por meio de metodologia qualitativa. A observação participante e as entrevistas semiestruturadas (através da seleção de participantes por amostragem 'bola de neve') foram utilizadas como técnicas de pesquisa. A observação participante foi realizada em sete meses e se deu em dois momentos distintos durante 0 ano de 2017. Durante os três primeiros meses acompanhamos uma fotógrafa em jogos do campeonato mineiro e
} 
jornalistas ${ }^{2}$ que trabalharam ou estavam trabalhando na cidade de Belo Horizonte. ${ }^{3}$ Nesse sentido, apresenta-se inicialmente o perfil das mulheres que trabalham nesse campo. Em seguida, são tecidas considerações sobre a trajetória profissional, as esferas possiveis de serem ocupadas para progredir na carreira, os constrangimentos com os quais se deparam as mulheres que escolhem se inserir no jornalismo esportivo e as táticas utilizadas por elas para se desvencilharem dessas situações.

\section{Retrato do perfil das mulheres no jornalismo esportivo em Belo Horizonte}

De um total de 38 mulheres entrevistadas que trabalhavam ou trabalharam no campo do jornalismo esportivo, a grande maioria nasceu na capital Belo Horizonte: 26 entrevistadas. Das outras 12 entrevistadas, oito vieram de cidades do interior de Minas Gerais (Santa Luzia, Itabira, Montes Claros, São João Del Rei, Boa Esperança, Carmópolis de Minas, Itamarandiba e João Monlevade), uma da Região Metropolitana de BH (Contagem) e uma de outro estado (Fortaleza, Ceará).

Os dados das entrevistas indicam que 20 dessas profissionais estão na faixa etária de 30 a 39 anos, seguidas por nove que estão entre 20 e 29 anos, oito entre 40 e 49 anos e uma na faixa de 50 a 59 anos. Quanto ao estado civil, 20 jornalistas se declararam solteiras, 14 casadas, três divorciadas e uma escolheu não informar. Quanto à questão de cor da pele, 23 se autodeclararam brancas, quatro pardas, três negras e oito prefeririam não responder. Todas se declararam mulheres heterossexuais.

O grau de escolaridade de 34 delas é superior completo, destas, cinco possuem pósgraduação lato sensu e/ou especialização e quatro possuíam, à época das entrevistas, grau de escolaridade superior incompleto - uma fotógrafa e três estagiárias. Ainda com relação à formação, 27 entrevistadas estudaram ou estavam estudando em universidades particulares. No momento em que foi realizada a entrevista, 26 declararam trabalhar com futebol e 12 não trabalhavam ou abandonaram a profissão. Das 38 entrevistadas, 15 trabalharam ou estavam trabalhando em emissoras de televisão, dez em emissoras de rádio, seis em redação de jornal e sete em outras áreas do jornalismo esportivo.

A partir das entrevistas realizadas com essas 38 jornalistas foi possível construir um perfil sobre as mulheres que trabalham no campo do jornalismo esportivo. Em sua maioria, possuem entre 30 e 39 anos, são solteiras, brancas, heterossexuais e nascidas em Belo Horizonte. Possuem alto grau de escolaridade - a maioria tem graduação na área de jornalismo, estudou em instituições particulares de ensino superior e trabalha em emissoras de televisão.

Certamente esses dados se constituem como uma fotografia momentânea composta pelas profissionais entrevistadas. Não obstante, os dados coletados apontam para alguns indícios importantes que devem ser ressaltados ao se pensar a dinâmica de gênero e suas intersecções no campo do jornalismo esportivo.

O primeiro indício considerado importante a se ressaltar é a grande quantidade de mulheres na faixa entre 30 e 39 anos, como também as solteiras que compõem o campo de trabalho, o que sugere o envelhecimento feminino como um interdito para ocupar certas arenas do campo do jornalismo esportivo. Ao contrário dos colegas de profissão, as profissionais que são recrutadas para trabalhar na televisão estão submetidas a normas de beleza, de boa aparência e padrões estéticos vigentes na mídia brasileira contemporânea. Independentemente da qualidade do trabalho como repórter, apresentadora ou âncora, as mulheres consideradas fora do padrão de idade e de beleza são identificadas como inapropriadas para ocupar esse espaço (CHAMBERS; STEINER; FLEMMING, 2004) e têm sido demitidas por esses motivos (VAN ZOONEN, 1998). Como revela uma das interlocutoras:

Elas têm que ser apresentáveis, a repórter não pode ser feia, não pode ser velha. Têm que estar com o corpo de atleta. Mas a gente vê homens velhos, fora de forma, nada esteticamente, classicamente beleza de televisão [...] quando ela é permitida estar nesse meio, ela tem que estar bonita. (Interlocutora 05, 40 anos, casada, heterossexual, branca, superior completo).

nos últimos quatro acompanhamos uma estagiária de uma rádio que cobria a equipe do América Futebol Clube-MG. Os dados coletados foram analisados de maneira interpretativa.

${ }^{2} \mathrm{O}$ anonimato de todas as 38 interlocutoras que concederam entrevistas foi mantido. Desse modo, no decorrer deste texto foram utilizados nomes fictícios e/ou uma sigla - com informações sobre idade, estado civil, orientação sexual, cor de pele/raça e grau de escolaridade - para identificá-las.

${ }^{3}$ É importante ressaltar que das 45 jornalistas filiadas à AMCE 12 foram entrevistadas no decorrer da pesquisa que deu origem a este artigo. Não tivemos acesso a 33 jornalistas filiadas à AMCE por uma série de fatores: algumas atuavam em cidades do interior de Minas Gerais, outras se recusaram a participar da pesquisa e as demais foram impedidas devido ao contrato de exclusividade de imagem com a emissora para a qual trabalhavam. As 26 jornalistas entrevistadas e que não estavam cadastradas na AMCE foram indicadas por uma das 12 cadastradas. Esse número suplementar assinala para uma rede de jornalistas que exerce seu ofício sem o cadastramento ou que já exerceu, em algum momento de sua carreira, uma atividade no jornalismo esportivo e manteve algum vínculo com a jornalista que a indicou para conceder a entrevista. 
O segundo indício aponta para um campo de trabalho em que as empresas têm dificuldades de conciliar a tensão entre trabalho e família, o que pode ser observado pela quantidade de mulheres solteiras que compõem seus quadros. Essa tensão entre vida pública e vida privada que Silvana Andrade (2014) identifica como um desafio entre as executivas que almejam ser consideradas mulheres de sucesso apresenta-se com alguma similaridade às jornalistas esportivas. Como apontam Chambers, Steiner e Flemming (2004), no contexto europeu e norteamericano, as mulheres que trabalham com jornalismo são jovens e solteiras, quando comparadas aos seus colegas. Aquelas que cogitam construir família tendem a abandonar o campo.

$O$ argumento dessas autoras coincide com os dados e as narrativas coletadas com as profissionais de Belo Horizonte. A interlocutora R7 (34 anos, casada, heterossexual, branca, superior completo) revela que se casou, teve filhos e parou de atuar nessa área. Apesar de trabalhar na parte administrativa de uma escola, pensa em voltar a trabalhar com futebol mesmo sabendo das dificuldades: "Não tem fim de semana, não tem feriado, não tem noites, mas futebol é a minha paixão." Outras narrativas coletadas apontam para a ausência de vida social fora do campo do jornalismo esportivo, pois, cobrindo futebol, trabalha-se em horários e dias que impossibilitam manter uma relação afetivo-sexual e relações familiares.

O terceiro indício assinala a heterossexualidade compulsória desse campo. Sabe-se que as mulheres quando praticam esportes são escrutinadas sobre sua identidade sexual e sua feminilidade (Ann HALL, 1990; ADELMAN, 2003). Em outras palavras, as instituições esportivas estabelecem um controle sobre o que seria o corpo feminino ideal e uma orientação sexual aceitável pela perspectiva heteronormativa. As acusações de homossexualidade dirigidas a atletas e treinadoras contribuem não somente para que elas permaneçam silenciadas, negando ou se desculpando por sua identidade e orientação sexual, como também adotem uma imagem heterosexy para se protegerem das violências - desde agressões físicas e sexuais até a demissão e o ostracismo - produzidas pelo estigma de lesbianismo nos esportes (Pat GRIFFIN, 2002).

Por fim, verifica-se uma pequena quantidade de mulheres que se autodeclararam negras trabalhando com o jornalismo esportivo em Belo Horizonte. Das interlocutoras entrevistadas que se declararam negras, duas estavam estagiando em uma rádio e uma havia abandonado o campo do jornalismo para seguir outra carreira. No entanto, não é apenas o número reduzido de mulheres que se declararam negras que chama a atenção, soma-se a isso a relutância das interlocutoras em declarar sua raça e cor de pele e, ainda, o desconforto sobre essa indagação.

De fato, outros estudos que se debruçam sobre o jornalismo esportivo, como o de Boyle e Richard Haynes (2009) na Grã-Bretanha, ou o de Creedon (1994a) nos Estados Unidos, apontam para as dificuldades encontradas por mulheres negras e de outras minorias para se inserirem nesse campo. O estudo de Boyle e Haynes chama atenção para o racismo casual nas relações entre jornalistas, atletas, treinadores e dirigentes no caso britânico. Creedon, por sua vez, aponta para o minúsculo número de mulheres negras que cobrem esportes nos jornais americanos e os aborrecimentos e importunos sofridos por elas. Além disso, a dupla alteridade da mulher negra submetida ao machismo e ao racismo concomitantemente (FERNANDES, 2016), a dificuldade de acesso ao mercado de trabalho e as limitações impostas pelos padrões de beleza e 'boa aparência' para o recrutamento (Maria A. BENTO, 1995; CARNEIRO, 2016) parecem ser indícios para pensar tanto na ausência dessas mulheres no campo do jornalismo esportivo quanto no desconforto em tornar visível a variável raça em suas declarações.

Nesse sentido, observa-se que as limitações impostas pelo padrão de beleza midiática interdita a presença de mulheres negras de qualquer faixa etária no jornalismo esportivo na televisão, contribuindo para estabelecer a "[...] recorrência abusiva, a inflação de mulheres loiras, ou da 'loirização' na Televisão brasileira [...]” (CARNEIRO, 2016, p. 152). Fenômeno este que não passa despercebido às interlocutoras que se declararam negras, como aponta a interlocutora R8 (22 anos, solteira, heterossexual, negra, superior incompleto): "Na TV, procuram o estereótipo bonita, alta, loira. Nunca vi uma negra de cabelo cacheado [...], sempre vai trocando as apresentadoras e elas são loiras de cabelo liso, loiras de cabelo liso."

Essas questões indicam um ambiente de trabalho não favorável para mulheres que não sejam identificadas como brancas, jovens, solteiras e heterossexuais. Esses indicadores da cidade de Belo Horizonte são similares aos dados coletados por Heloiza G. Herscovitz (2000) entre homens e mulheres jornalistas no início do século XXI e por Figaro e Claudia Nonato (2017), 17 anos mais tarde, na cidade de São Paulo, assim como também se assemelham aos dados da pesquisa da Artigo 19 (2017) realizada nas cidades de São Paulo, Brasília e Rio de Janeiro.

No entanto, mesmo as mulheres que se adequam mais ou menos ao padrão acima descrito enfrentam barreiras para ocupar espaços no jornalismo esportivo. E é sobre os limites e as possibilidades de se inserir e permanecer no campo que as seções seguintes se ocupam.

\section{Trajetória profissional: deslocamentos e circulação}

A trajetória das mulheres no jornalismo esportivo em Belo Horizonte é marcada pelo deslocamento, circulação e instabilidade nesse mercado de trabalho. Observa-se nessas trajetórias 
que o deslocamento se dá em três direções. Uma que fica confinada ao circuito de empresas existente em Belo Horizonte, uma segunda em que o deslocamento extrapola o estado de Minas Gerais e uma terceira em que o deslocamento pode ultrapassar as fronteiras brasileiras.

O deslocamento dentro do circuito das empresas de comunicação esportiva de Belo Horizonte, onde, segundo elas, o mercado é muito restrito, ${ }^{4}$ se estabelece pela circularidade entre emissoras de televisão, rádio e redações. Nessa circulação interna, o padrão de entrada no mercado de trabalho e sua permanência se desenrola da seguinte maneira: as mulheres geralmente se graduam em universidades privadas, onde puderam estagiar em meios de comunicação da própria universidade, e a entrada no mercado de trabalho se dá por estágio em um meio de comunicação - televisão, rádio e jornal -, entretanto, quando se encerra a experiência de estágio, são poucas as que são efetivamente contratadas. No caso de empresas públicas, isso acontece devido ao recrutamento ser realizado por concurso público, mas, no caso das empresas privadas, as justificativas de não contratação apresentam-se com um leque variado que vai da ausência de vagas na editoria dos esportes até a crise econômica.

Nesse momento de dificuldade de contratação, a circulação se intensifica e aqui se inicia um processo caracterizado pela sazonalidade e instabilidade do ofício, no qual elas fazem substituições de férias das profissionais contratadas. A essas substituições acrescentam-se, concomitantemente, os trabalhos como freelancers, assessoria de imprensa de clubes e/ou apresentação e/ou reportagem de canais dos clubes de futebol da cidade.

Sem perspectiva de trabalho em Belo Horizonte, algumas apostam em deslocamentos para outros estados brasileiros. São Paulo e Rio de Janeiro são os centros mais procurados em busca de oportunidades no campo dos esportes. E a partir desses centros o deslocamento para outros países torna-se uma possibilidade mais palpável, mesmo em condições precárias, já que as emissoras de televisão enviam correspondentes para cobrir os campeonatos europeus. De acordo com os relatos coletados entre as interlocutoras de Belo Horizonte, esse deslocamento internacional raramente ocorre para se realizar a função de correspondente de emissoras de televisão. É mais frequente o deslocamento para a realização de cursos de aperfeiçoamento ou de pós-graduação em países europeus.

Em muitos casos, há um afastamento do campo esportivo por um tempo e inicia-se a circulação em outras instituições que não necessariamente trabalham com esporte. Elas se tornam assessoras de políticos, instituições comerciais, de saúde, escolares, de marketing, entre outras. As que abandonam definitivamente a carreira revelam que decidiram fazê-lo para constituir família, para solucionar problemas de saúde familiar, pela pouca remuneração proveniente desse campo e por motivo de segurança de um emprego público.

\section{Espaços ocupados, possibilidades de progressão e (múltiplos) constrangimentos}

O entendimento de que o campo do jornalismo esportivo, assim como o do futebol, é um espaço histórico e culturalmente masculino é levado em conta pelas interlocutoras em suas narrativas para dar sentido à presença das mulheres, às dificuldades de progressão na carreira e aos espaços possíveis de serem ocupados por elas nesse campo:

[...] já entrei sabendo que esse espaço historicamente não é para mulher. Eu vou ter o dobro do esforço para acreditarem em mim. Eu vou ter o dobro do esforço para passar credibilidade. Porque eu sou uma mulher, porque eu falo de futebol [...] para muitas pessoas isso é uma coisa descontextualizada. Mulher e futebol não se juntam. Justamente por essa construção histórica. (Interlocutora R4, 20 anos, solteira, heterossexual, parda, superior incompleto).

Quando enfocam essas questões, as narrativas estabelecem perspectivas diferentes para compreendê-las. Assim, por um lado, apresentam-se declarações nas quais a agência individual, o esforço e o interesse pessoal permitem a presença das mulheres nesse espaço. Aqui há uma negação de gênero, uma neutralização de gênero (Raewyn CONNELL, 2016) ou mesmo uma "fadiga de gênero" (ANDRADE, 2014, p. 136). Por outro lado, apresentam-se declarações que apontam para as dificuldades e desafios enfrentados pelas mulheres, independentemente de sua competência, esforço e interesse, limitando sua presença em um espaço percebido como hostil. Aqui há uma afirmação e uma compreensão de posicionamentos de gênero que perpassam esse mesmo domínio.

\footnotetext{
${ }^{4}$ As que escolhem seguir carreira em emissoras de rádio cobrindo futebol e demais esportes têm a possibilidade de se inserir nas rádios Itatiaia, Inconfidência, Band, 98FM e Superesportes. As que optam por seguir carreira em emissoras de televisão têm como alternativas as TV de clubes - TV Galo, TV Cruzeiro, TV América -, a TV do Estádio Governador Magalhães Pinto, a TV Alterosa, filial da SBT em Minas Gerais, Band Minas, TV Horizonte e a Rede Minas. Apesar de ser um espaço cobiçado, poucas chegam a emissoras como a Rede Globo e seu canal de esportes, o SporTV. As que escolhem trabalhar em redações estão nos jornais O Tempo, Super Notícias, Hoje em Dia e Estado de Minas. Há também aquelas que escrevem para blogs como o Vavel Brasil e sites como globo.com, entre outros.
} 
As jornalistas que abraçam a primeira perspectiva argumentam que não se trata de desigualdade de gênero, pois, segundo as interlocutoras que mobilizaram essa narrativa, falar de desigualdade de gênero é uma questão anacrônica, tendo em vista que no passado era muito pior e no presente não há mais discriminações como antes. ${ }^{5}$ Trata-se, portanto, de coragem, capacidade e competência profissional para progredir na carreira e ocupar certos espaços. Como afirma uma das jornalistas entrevistadas: "Gênero, não! Capacidade, competência e respeito" (Interlocutora TV1, 52 anos, casada, heterossexual, branca, superior completo). Certamente não são todas as mulheres capacitadas para tal, mas se quiserem - sempre há as que querem existe espaço para se destacar, para ocupar cargos de chefia.

Nessa perspectiva, a agência individual determina o espaço e a função a ser ocupada. Tudo se passa como se o projeto individual fosse autônomo e independente das condições do contexto e do círculo social no qual o indivíduo se insere. Em outras palavras, a margem de manobra para alcançar certos objetivos individuais está descolada das limitações engendradas pelo campo de possibilidades da realidade social (Gilberto VELHO, 2004). E se não há mais limitações estruturais torna-se aceitável culpabilizar somente os indivíduos pelas suas escolhas em ocupar ou não certas esferas, como aponta uma das jornalistas:

[...] eu acho que a culpa é da mulher de não aproveitar o mercado, de não se interessar. Por que você acha que não despontam? Porque não procuram se despontar. Eu tenho que provar no cargo que eu ocupo que eu preciso ser melhor do que o homem que estava antes de mim. Porque se eu não for boa, tanto quanto ou mais do que ele, vai vim qualquer outra pessoa, ou mulher ou homem, e vai ocupar meu cargo. Então vai depender muito de mim. A culpa é muito das mulheres, 'ah, esse é um mercado muito masculino', e não se preocupam, sabe? Não adquirem conhecimento. Não entram no mundo com toda força e com toda coragem. Nós temos mulheres que pilotam avião, temos engenheiras na Marinha, temos mulheres em todos os ramos. Por que é que no futebol não? Quando nós vamos no Mineirão ou no Independência fazer jogos, na beira do campo, tem várias mulheres. Ainda é uma porcentagem, uma parcela pequena? É. Mas a culpa é nossa [...] (Interlocutora R9, 44 anos, casada, heterossexual, superior completo).

No sentido de fundamentar essa percepção - das possibilidades de ascensão na carreira por esforço próprio - as interlocutoras se referem a mulheres que ocupam ou ocuparam posições de prestígio e chefia em diretoria de clubes, federações e emissoras. Essas narrativas apontam para um problema que Ross (2001) identifica no campo do jornalismo, que o sucesso individual nesse campo encobre as dificuldades vivenciadas por um número grande de mulheres. Essa argumentação parece fazer sentido à medida que, nos depoimentos das jornalistas de Belo Horizonte, as exceções tornaram-se modelos para se atingir uma posição privilegiada, pois eram enumerados sempre os mesmos quatro ou cinco nomes de jornalistas consagradas como exemplos de que o espaço do jornalismo esportivo não discrimina mulheres e que seria possível ocupar posições de destaque.

Por último, mas não menos importante, a pouca presença das mulheres no jornalismo esportivo também é percebida como uma questão da agência individual. É o gosto pessoal e a infinidade de subáreas do jornalismo a serem escolhidas que determinam a não adesão ao jornalismo esportivo pelas mulheres. Há o entendimento de que a maioria das mulheres não gosta de futebol, embasado pela experiência pessoal com o grupo de relações de amizade - "entre as amigas, sou a única que gosta de futebol", como uma das entrevistadas afirmou. Ademais, apontam que o campo do jornalismo é muito grande e é preciso considerar a opção das mulheres por outras áreas que não a esportiva. Também é necessário considerar que o espaço do jornalismo esportivo em Belo Horizonte é pequeno. Assim, a restrição do mercado de trabalho e, consequentemente, a competitividade maior são entendidas como a razão da pequena quantidade de mulheres no campo.

As jornalistas que abraçam a segunda perspectiva não somente apontam para a desigualdade de gênero, mas também para o machismo e o sexismo incorporados ao campo. É importante ressaltar que, dos marcadores sociais da diferença, gênero foi a categoria mais empregada para reforçar as desigualdades no campo do jornalismo esportivo.

Para essas profissionais existem múltiplos "tetos de vidro" (Joan ACKER, 2009; ANDRADE, 2014) que limitam a ascensão das mulheres a cargos de chefia e determinam quais os espaços legítimos e permitidos de serem ocupados por mulheres.

Uma interlocutora aponta para a dificuldade de progressão na carreira revelada pela sua vivência profissional. Em sua argumentação reside a percepção de que há barreiras marcadas

\footnotetext{
${ }^{5}$ As jornalistas com mais tempo de carreira relatam que não podiam entrar nos vestiários para entrevistar os jogadores. Duas delas relataram incidentes de quando lhes foi permitido o acesso ao vestiário: como forma de intimidação, os jogadores deixavam a toalha cair, permaneciam nus durante a entrevista e tocavam a própria genitália. E acrescentam que nas salas de imprensa do Estádio Mineirão não havia banheiro feminino, nem nos centros de treinamentos dos clubes de futebol. Hoje em dia, as entrevistas são realizadas em uma sala preparada para isso, são coletivas dadas pelo técnico e um ou outro jogador para todos os meios de comunicação e há sanitários femininos tanto nas salas de imprensa dos estádios quanto nos clubes.
} 
pelo gênero que tornam desigual a possibilidade de ascensão na carreira. Portanto, segundo as narrativas dessas jornalistas, não basta ser competente e qualificada para romper com o 'teto de vidro', mas é necessário, mesmo que isso não seja uma garantia de alcançar posições de mando, 'ralar mais' e 'se esforçar em dobro' para tentar atingir a mesma posição que seus colegas homens alcançam com maior tranquilidade. Elas se queixam de que eles ascendem mais rapidamente e recebem os melhores salários - "os homens são os grandes nomes do jornalismo".

Na troca de editor, nunca se pensou numa editora. Acho que o jornalismo inteiro é assim. Fico pensando na economia. Você não vê mulher na economia. É difícil sair desse lugarcomum, porque capacidade tem, a formação da mulher tem mais curso, a formação dela é melhor, de mais qualidade porque ela estuda mais, mas, mesmo assim, a luta dela dentro do jornalismo é muito grande [...] porque não é qualidade do trabalho, sabe? Também não é uma discussão de capacidade e conhecimento. Isso vai da direção, dos donos das organizações de comunicação ou preferência que é mais uma barreira. (Interlocutora JR2, 45 anos, solteira, heterossexual, parda, superior completo).

Quanto aos espaços legítimos e permitidos a serem ocupados, estes também são marcados por gênero. Tudo leva a crer que a mesa-redonda, a cabine de transmissão e a chefia de editoria são espaços de reserva masculina legítima e de interdição feminina, como aponta uma das jornalistas:

A cabine é um lugar que mulher não é bem-vinda. Isso é fato. [...] Eu acho porque a cabine é o ápice do futebol. Ali a gente não entra. Ali a gente não é bem-vinda. Eles não querem a gente ali. Existe um muro de concreto, assim. O máximo que uma mulher entra na cabine é uma produtora que vai levar uma informação prum narrador, por exemplo. E a cabine é o ambiente deles e eles se acham os tais [...] talvez eles achem que a gente nem é capaz de estar ali. (Interlocutora TV9, 35 anos, solteira, heterossexual, branca, superior completo).

Ao contrário da apresentação de programas esportivos, a reportagem, "a cozinha da redação e das emissoras" (produção, pesquisa e edição) é um espaço feminino possível. As narrativas carregam indícios de que, quando transcendem os espaços considerados masculinos e ocupam posições de autoridade e poder, pesa sobre essas mulheres suspeitas sobre suas habilidades e acusações de uso da sedução para tal. Além disso, elas são acusadas de se comportarem como homens e têm sua feminilidade questionada (Catharine MACKINNON, 1987), são referidas pelos colegas como "piranhas", "megeras" e "bruxas" (ANDRADE, 2014), e têm sua autoridade contestada (CONNELL, 2016).

O comportamento machista é apontado dentro das redações e emissoras como o padrão de relação entre pares profissionais, tornando o ambiente intimidador para as mulheres. Nas narrativas, é frequente a queixa de não serem ouvidas quando propõem as mesmas pautas que são ouvidas quando a proposta é apresentada pelos colegas homens. Inclui-se nessa dinâmica o entendimento de que são ignoradas pelos colegas quando exprimem opiniões sobre o desempenho de jogadores e equipes, como também uma postura desigual dos chefes em relação às escolhas para cobrir determinados eventos e as eventuais falhas masculinas e femininas.

A desigualdade marcada por gênero também se reflete em jogos importantes, como final de campeonato ou jogos da Seleção Brasileira. Nesses momentos, elas são preteridas frente aos colegas homens. Estes têm a prioridade para participar desses eventos justificada pela experiência e pelo traquejo em cobri-los. No entanto, como afirma uma interlocutora: "[cobrir] final não é fácil. Então, entre as mulheres experientes e os homens, eles mandam os homens. É raríssimo mandar mulher, você já reparou isso: raríssimo!" (Interlocutora TV7, 26 anos, solteira, heterossexual, branca, superior completo).

O comportamento agressivo de chefes e colegas, desde gritos até condescendências irônicas, é comum segundo narram as interlocutoras. O mesmo ocorre quando questionam os técnicos nas entrevistas coletivas ou se posicionam contrariamente ao desempenho dos jogadores. Em relação a constrangimentos sofridos nas entrevistas coletivas, as interlocutoras relatam preconceitos implícitos. Elas percebem olhares, risos e expressões faciais dos colegas de profissão e dos entrevistados como um indicativo do mal-estar relativo à sua condição de mulher num espaço masculino:

O Leão quando foi técnico do Galo. Era pra mim um dos mais difíceis de lidar. E teve uma vez que eu fiz uma pergunta pra ele que o jogo teve um segundo tempo muito diferente do primeiro e o Atlético estava fazendo o returno do campeonato muito diferente do primeiro turno. Eu fiz uma pergunta pra ele fazendo um paralelo disso e o que tinha feito os jogadores mudarem tanto de postura no segundo tempo [...] e ele me respondeu na coletiva 'você está muito ácida, o time ganha e você está fazendo uma pergunta dessa. Eu vou te levar para tomar um sorvete de doce de leite para ver se você fica mais doce'. Esse é um tipo de coisa que ele não falaria para um colega homem. Apesar de que uma resposta ele dava em todo mundo. (Interlocutora R5, 37 anos, casada, heterossexual, branca, superior completo). 
Segundo os relatos apontam, nesse campo, há uma premissa que diz que "homem acha que mulher não entende de futebol" (Interlocutora TV6, 31 anos, solteira, heterossexual, branca, superior completo). Desse modo, é frequente a avaliação cotidiana do conhecimento da profissional sobre questões relativas às regras do jogo, às táticas e à familiaridade com os personagens e às partidas históricas no intuito de legitimar a presença dessas mulheres nesse espaço. As avaliações cobrem desde o questionamento da regra do impedimento até a escalação de determinado time e o resultado da partida da decisão do campeonato regional de décadas passadas. Essas avaliações são frequentemente realizadas em forma de brincadeiras depreciativas e deboches por colegas homens.

É frequente nas narrativas dessas jornalistas a percepção de que a princípio seus colegas de trabalho homens desconfiam da sua capacidade de entendimento do esporte, no caso, o futebol, e da competência em enfrentar e resolver situações difíceis. Portanto, além de avaliadas, elas têm que 'provar que entendem' e 'que dão conta'.

Entretanto, se são bem-sucedidas e conseguem um furo de reportagem (assim como ocorre quando progridem na carreira e ocupam cargos de destaque), pesa sobre elas a acusação de erotização da competência na coleta de informações. São acusadas, por exemplo, de se utilizarem de relações sexuais para conseguir informações privilegiadas: "conseguiu o furo porque dormiu com o jogador" ou "só entrou ali porque 'deu' para alguém, porque tem peito e bunda" (Interlocutora TV12, 39 anos, solteira, heterossexual, branca, superior completo), denigrem os pares.

Essas acusações que recaem sobre a honestidade e moral sexual são recorrentes no cotidiano das jornalistas como indicam as narrativas coletadas por Natália Mazotte e Mônica Toste (2017) com profissionais de cidades diversas, como Brasília, São Paulo, Rio de Janeiro e Porto Alegre. Esse é um fenômeno que não é estranho às jornalistas estrangeiras, segundo revela a literatura que aborda a intimidação das mulheres nas redações em vários países (THEBERGE; CRONK, 1994; MILLER, P.; MILLER, R., 1995; VAN ZOONEN, 1998; BOYLE, 2006).

Mesmo diante de tanta violência, que, aqui estão sendo consideradas eufemisticamente como constrangimentos, há uma reticência enorme em relatar flertes e assédios sexuais. A grande maioria argumenta que nunca sofreu com nenhum dos dois comportamentos. Dizem que 'cantadinhas' e brincadeirinhas são comuns entre colegas, jogadores e diretores. Abordagens acontecem o tempo todo, dizem. Elas são convidadas para jantar, 'tomar um vinho', recebem presentes - desde flores e chocolates até aparelhos domésticos, como ar-condicionado, por exemplo. Os assessores de imprensa dos clubes pedem o número de telefone em nome dos jogadores e elas recebem mensagens destes por meio de aplicativos como o WhatsApp. Quando circulam pelos centros de treinamentos ou estádios em busca de informações para uma reportagem, recebem propostas sexuais em troca de informações exclusivas; muitos de seus interlocutores oferecem carona e os mais audaciosos chamam para ir ao motel. Mas nada disso é percebido como assédio ou violência por algumas delas.

Tudo leva a crer que há uma naturalização dessas experiências nesse espaço. O fardo de suportar esses constrangimentos parece algo que deva ser vivenciado para que elas possam se inserir nessa profissão. Várias interlocutoras entendem que, por ser um espaço masculino, as normas masculinas dessa instituição são tão cristalizadas que não há espaço para transformações. Se tradicionalmente foi assim, assim será eternamente.

Ora, nunca é demais apontar para a dimensão de dominação que faz com que elas se resignem a suportar as relações às quais são submetidas pelos homens que ocupam posições de poder e seus cúmplices nessas esferas. Silenciar-se sobre o assunto ou trivializar, naturalizando a ocorrência desses comportamentos quando se trata de colegas, chefes, dirigentes, técnicos ou jogadores, pode ser pensado como uma maneira de proteger - mesmo que com medo, mesmo que inconscientemente - a sua permanência e viabilidade de trabalho nesse mercado.

A narrativa de assédio e violência é revelada, entretanto, quando a interação é estabelecida com outros atores no campo dos esportes. Geralmente quando elas falam de torcedores é que a prática de assédio e violência aparece. São vários os relatos de torcedores que tentam beijá-las, abraçá-las e são agressivos se elas não os entrevistam. Elas apontam que eles as abordam provocativamente e utilizam de linguagem ofensiva e as cortejam indecorosamente, sempre em grupos. Quando se posicionam e reagem são insultadas com termos como: 'vagabundas', 'putas' ou 'seu lugar é no fogão'.

A interação com a torcida é descrita sempre de maneira tensa. As jornalistas contam casos de violência verbal e incidentes de quase violência física com muita frequência em seus relatos. Segundo a maioria das entrevistadas, esse é um dos motivos ${ }^{6}$ para não revelarem abertamente o time de coração: o medo da violência de torcedores.

${ }^{6}$ Outro motivo enumerado para não revelar por qual agremiação elas torcem se dá em relação ao mercado de trabalho em Belo Horizonte. Elas acreditam que, ao expor sua paixão clubística, a possibilidade de entrada no mercado de trabalho, que já é reconhecidamente restrito, pode se tornar inviável. Sendo assim, tudo se passa como se, ao identificarem o time pelo qual elas torcem, as empresas que propagam a ideia de neutralidade esportiva não pudessem contratá-las sem o descrédito de sua audiência. 
Por todas essas questões enumeradas, as mulheres que se inseriram e continuam trabalhando com o jornalismo esportivo entendem que o espaço não é atraente para qualquer mulher. As mulheres mais 'descontraídas', que têm 'jogo de cintura', aquelas que 'impõem respeito', são as que conseguem transitar e almejar sucesso nesse campo profissional.

\section{Sobre 'impor respeito' e suas estratégias}

Ao enfrentar as adversidades nesse espaço, o discurso que mais transparece nas narrativas é o de impor o respeito. A estratégia de impor e manter o respeito se dá de diferentes formas. $O$ controle e a distância corporal, o controle das emoções, a evitação de relações de amizade e intimidade e manter a postura de quem conhece minuciosamente a história dos indivíduos que circulam ou circularam pelo esporte fazem parte do cabedal da noção de impor respeito.

O controle e a distância corporal são maneiras de impor o respeito na profissão. Essa estratégia requer uma preocupação constante com as vestimentas e adereços, além de uma preocupação em tornar o corpo invisível para os olhares masculinos. O que ocorre é uma ocultação corporal no sentido de deixar as formas corporais escondidas e tornar o corpo o mais distante possível do desejo masculino. Trata-se de uma estratégia racional que demanda que, ao circular em espaços como os campos de jogo e treinamento, sejam tomados certos cuidados. A blusa amarrada na cintura, as roupas largas, o cabelo preso, o uso restrito de maquiagem e adereços, o olhar para baixo no intuito de não trocar olhares são artifícios primordiais para se proteger e manter o respeito. Além disso, o corpo deve ser mantido à distância nas interações sob o risco de interpretações dúbias. Portanto evitam o contato, não dão beijos ao cumprimentarem (estendem a mão em vez disso); ainda, evitam conversar de maneira empática. Esse distanciamento exige uma alteração na forma de ser e de se relacionar dessas mulheres. Elas dizem que no espaço de trabalho elas não agem com naturalidade. Se são expansivas e tenras em outras esferas de sua vida privada, na vida pública são sérias e duras para relacionarem-se com seus interlocutores, dizem.

Essas profissionais são proibidas, de uma certa forma, de manter relações erótico-afetivas com jogadores, técnicos e dirigentes sob o perigo de perderem credibilidade como jornalistas. Não que essas relações afetivas não aconteçam, mas, como é percebida como uma ameaça para a continuação da carreira no jornalismo esportivo, todas as entrevistadas negaram ter se envolvido com jogadores, mas afirmaram que conhecem jornalistas que o fizeram.

Muitas não estabelecem nem relações de amizade com os seus interlocutores e dizem que manter o distanciamento é uma forma de não passar por constrangimentos:

O meio é completamente masculino. A postura sua também. Você tem que estar se policiando o tempo inteiro. A busca de fontes no meio também é complicada. Sei lá, eu tenho colegas que podem se encontrar com o jogador no final de semana ou sair para jantar com técnico e criar uma fonte. Agora, imagina você, mulher, sentar no restaurante com um técnico de futebol? Isso ainda é uma barreira. Vão ter várias interpretações aí, né? Então é sempre mais difícil. (Interlocutora JR2, 45 anos, solteira, heterossexual, parda, superior completo).

A tensão nas relações entre os jornalistas e as jornalistas no esporte e suas fontes de informação se apresenta no difícil equilíbrio da lealdade entre esses atores, o que Normand Bourgeois (1995) chama de "sociodrama". De um lado, o jornalista e a jornalista precisam manter a autonomia de suas análises críticas independentemente da relação estabelecida com sua fonte e assim manter a aparência de neutralidade e, consequentemente, credibilidade entre seus empregadores e leitores. Por outro lado, a informação privilegiada depende do vínculo estabelecido com sua fonte em uma ação colaborativa. Esse vínculo pode extrapolar o âmbito público e "[...] se tornar mais forte no âmbito privado, uma vez que se misturam em boates, cassinos, festas particulares, clubes de golfe e viagens de férias." (Richard GIULIANOTTI, 2002, p. 156). A tensão diminui quando o jornalista ou a jornalista consegue equilibrar os dois polos de maneira que possa mesclar elogios e críticas dando maior visibilidade ao esporte e contemplando as expectativas de jogadores, dirigentes, empregadores e leitores.

O fato é que, ao pensarem as tensões e os dramas na relação entre jornalista e informante, esses autores não consideraram a relação de gênero como algo excedente nessa interação. A barreira, como mencionada na citação da Interlocutora JR 2, é muito maior e o equilíbrio depende do que elas chamam de 'impor respeito'. Em outras palavras, elas não davam abertura para que os constrangimentos ocorressem, portanto, não ofereciam chances para que uma interação de trabalho fosse interpretada pelos seus interlocutores como paquera. Quando isso ocorria elas se utilizavam do 'jogo de cintura' para se desvencilhar da interação sem se mostrarem arrogantes ou agressivas e sem que, com a negativa, perdessem a fonte de informação.

Esse 'jogo de cintura' passa por levar a paquera para o nível da brincadeira e da jocosidade ou, ainda, realizar um desempenho de desentendimento, fingir que não entendeu ou não viu o que estava acontecendo e continuar o trabalho. Ainda como maneira de se protegerem, as jornalistas procuram fazer amizade com as companheiras dos jogadores e, por meio delas, agendar entrevistas 
ou realizar uma reportagem. Assim criam uma situação em que o flerte e o assédio serião interditados pela presença da esposa ou namorada. A aposta nessa aproximação é pela possibilidade de que, se ocorrer uma abordagem por parte do jogador, a jornalista pode mobilizar a família deste como trunfo para se livrar do constrangimento sem ter sua fonte ameaçada.

Evitar o confronto passa a ser a estratégia utilizada, assim, caso se sentissem ameaçadas pelas insistências de jogadores, dirigentes e colegas, diziam que eram casadas, noivas ou namoradas, mesmo não sendo de fato. Isso porque há a percepção de um código de honra entre homens - 'machos respeitam machos' - que incide sobre o controle de 'suas' mulheres. Um respeito baseado no medo e que "[...] deve desconfiar da predação dos outros homens, pelo que vive na ambiguidade da confiança da amizade e da desconfiança da virilidade predadora dos outros." (Miguel V. ALMEIDA, 1995, p. 68). É nesse sentido que a negativa seria entendida não como uma afronta, mas como uma questão compreensível para a conduta de mulheres equilibradas, moderadas, sérias, comprometidas e servis ao modelo cultural patriarcal e machista.

Manter-se informada sobre fatos passados e presentes da carreira do jogador pode ser uma maneira de impor respeito em momentos de entrevistas:

A mulher tem que se fazer respeitar, assim, por ser mulher, por ser um elemento novo naquele mundo deles. As perguntas têm que ser objetivas, você tem que provar que você conhece, que você, seu texto tem que ter informação, ser competente independente do sexo. (Interlocutora JR5, 44 anos, casada, heterossexual, branca, superior completo).

Assumir uma postura de quem possui conhecimento e sabe do que está falando foi reiterada diversas vezes como uma estratégia para escapar dos constrangimentos nessas interações. Uma das jornalistas revelou que, para entrevistar um jogador, ele condicionou a entrevista ao conhecimento dela do seu primeiro gol como profissional na carreira. Percebe-se, com isso, nesse e em outros tantos casos narrados, que a intimidação sofrida por meio da avaliação de conhecimento sobre detalhes da história do campo esportivo e seus personagens - no caso, aqui, o futebol - a que elas são submetidas pelos pares masculinos na redação é reproduzida em experiências com outros homens fora das redações. Tanto num espaço quanto no outro é necessário provar que se sabe. Algo que não encontra similaridade quando a interação é realizada por homens.

\section{Considerações finais}

Este texto abordou a trajetória profissional - marcada por deslocamentos, circulações e instabilidades -, as possibilidades e os limites de ocupação de espaços e construção de carreira por mulheres no jornalismo esportivo em Belo Horizonte. Ademais, revelou os constrangimentos a que elas são submetidas ao se inserirem nesse campo e as estratégias para minimizar e dar sentido a tais situações de maneira a se posicionarem e transitarem como mulheres jornalistas na esfera do esporte.

No decorrer do texto, por vezes, o foco da análise foi conduzido pelas desigualdades produzidas pela dinâmica de gênero nesse espaço. No entanto, ao construir um retrato de mulheres que trabalham no jornalismo esportivo em Belo Horizonte, foram apontadas outras categorias que se interseccionam com o gênero e afetam a presença (inserção e permanências) nessa esfera.

Nesse sentido, os indícios sobre os problemas relativos a idade, estado civil, assim como a autodeclaração racial e heterossexualidade compulsória, não somente podem ser pensados como um problema estrutural, mas também como limites para a agência individual nesse campo. O desconforto, a reticência ao declarar a cor da pele e a orientação sexual e as narrativas de neutralização da desigualdade de gênero ou a naturalização e silenciamento sobre flertes e assédios sugerem um investimento no posicionamento de determinada subjetividade - mulheres brancas, solteiras, heterossexuais - para se adequarem, e, consequentemente, serem cúmplices dos discursos e práticas dominantes nesse campo.

Como indica Henrietta L. Moore (2000), o investimento em determinada posição e a escolha de ação mobilizada por referência a uma subjetividade e não outra pode trazer benefícios pessoais em um determinado contexto. A autora argumenta ainda que assumir uma posição de sujeito e escolher ser cúmplice ou resistir às estruturas através da ação baseada em uma subjetividade específica, dentre as múltiplas e contraditórias que os sujeitos investem, não é uma escolha simples. Isso porque os discursos e práticas de poder variam historicamente, o que faz com que os benefícios de resistir ou ser cúmplice se embaralhem de tempos em tempos. Portanto, ao se identificar e escolher uma posição para agir, o sujeito mobiliza não apenas a sua percepção racional da situação, mas também a afetiva e a fantasia envolvida na agência e no posicionamento. Nas palavras da autora:

Nesse contexto a fantasia, no sentido de ideias sobre o tipo de pessoa que se gostaria de ser e o tipo de pessoa que os outros acreditassem que se é, tem claramente um papel a desempenhar. Tais fantasias de identidade se ligam a fantasias de poder e agência no mundo. (MOORE, 2000, p. 38). 
Essas vantagens momentâneas da cumplicidade permitem ocupar novos espaços, ascender na carreira e acumular poder, mas não transformam as estruturas dominantes, muito menos suas ideias, discursos e práticas. Da mesma forma, 'impor respeito' e 'jogo de cintura', embora sejam estratégias de proteção e de possibilidade de transição e de posicionamento no campo, falham como ação de resistência e se tornam cumplicidades. Isso ocorre, pois, ao controlar os comportamentos e maneiras de se vestir, ao se distanciar afetiva e corporalmente e ao realizar malabarismos para manter e não aborrecer as fontes de informação, elas acatam e reconhecem como legítimas essas práticas e suas dinâmicas nessa esfera.

Isso não significa, contudo, que elas não se indignem, mas tudo se passa como se, para ocupar esse espaço, fosse, necessariamente, preciso conviver com isso, que esse seria o preço a pagar para se inserir nesse universo masculino. Como também é possível perceber pelas narrativas, as ações para resistir e tentar alterar a dinâmica nessa estrutura seriam mobilizadas por um número muito pequeno de mulheres que seriam vozes dissonantes, ainda muito frágeis para realizar transformações significativas.

Enfim, o que se descortina no horizonte dessas mulheres é a percepção de que, mesmo sendo um espaço masculino, mudanças estão ocorrendo. Apesar de dissensos em torno das narrativas sobre as possibilidades e limites da inserção, permanência e sucesso dessas profissionais, há o consenso de que houve um crescimento na quantidade de mulheres que recentemente se inseriram no campo, as quais estão vivenciando um momento de transição constituído pela diminuição de desigualdade de gênero e aumento de oportunidades para adentrarem, ascenderem, ocuparem novos espaços e prosperarem na carreira na atual conjuntura no jornalismo esportivo.

\section{Referências}

ACKER, Joan. "From glass ceiling to inequality regimes". Sociologie du Travail, 51, p. 199-21 7, 2009.

ADELMAN, Miriam. "Mulheres atletas: re-significações da corporalidade feminina". Revista Estudos Feministas, Florianópolis, v. 2, n. 11, p. 445-465, jul./dez. 2003.

ALMEIDA, Miguel Vale de. Senhores de si: uma interpretação antropológica da masculinidade. Lisboa: Fim de Século, 1995.

ANDRADE, Silvana. Eu sou uma pessoa de tremendo sucesso: representações, identidades e trajetórias de mulheres executivas no Brasil. Rio de Janeiro: Mauad/FAPERJ, 2014.

ARTIGO 19. Gênero e mídia: um olhar de gênero para o ambiente de mídia brasileiro. São Paulo, Artigo 19/UNESCO, 2017. Disponível em https://artigo19.org/blog/2017/03/01/13860/. Acesso em $17 / 06 / 2019$.

BENTO, Maria Aparecida. "A mulher negra no mercado de trabalho". Revista Estudos Feministas, Florianópolis, v. 3, n. 2, p. 479-488, 1995.

BOURDIEU, Pierre. Sobre a televisão. Rio de Janeiro: Jorge Zahar Ed., 1997.

BOURGEOIS, Normand. "Sports journalists and their source of information: a conflict of interests and its resolution”. Sociology of Sports Journal, v. 12, n. 2, p. 195-203, 1995.

BOYLE, Raymond. Sports journalism: contexts and issues. London: Sage, 2006.

BOYLE, Raymond; HAYNES, Richard. Power Play: sport, the media and popular culture. Edinburg: Edinburgh University Press Ltd., 2009.

BRUM, Adriana; CAPRARO, André Mendes. "Mulheres no jornalismo esportivo: uma 'visão além do alcance'”. Movimento, Porto Alegre, v. 21, n. 4, p. 959-971, out./dez. 2015.

BRUSCHINI, Cristina. "Trabalho feminino: trajetórias de um tema, perspectivas para o futuro". Revista Estudos Feministas, Florianópolis, n. 1, p. 17-32, 1994.

BRYSON, Lois. "Challenges to male hegemony in sports". In: MESSNER, Michael; SABO, Donald (Eds.). Sport, men, and the gender order: critical feminist perspectives. London: Human Kinetics, 1990. p. 173-184.

CARNEIRO, Sueli. "Mulheres em movimento". In: RODRIGUES, Carla; BORGES, Luciana; RAMOS, Tânia Regina Oliveira (Orgs.). Problemas de gênero. Rio de Janeiro: Funarte, 2016. p. 149-168.

CHAMBERS, Deborah; STEINER, Linda; FLEMMING, Carol. Women and journalism. London: Routledge, 2004. 
CONNELL, Raewyn. Gênero em termos reais. São Paulo: nVersos, 2016.

CREEDON, Pamela. "Women in toyland: a look at women in American newspaper sports journalism". In: CREEDON, Pamela (Ed.). Women, media and sport: challenging gender values. London: Sage, 1994a. p. 67-107.

CREEDON, Pamela. "Women, media and sport: creating and reflecting gender values". In: CREEDON, Pamela (Ed.). Women, media and sport: challenging gender values. London: Sage, 1994b. p. 3-27.

DUNNING, Eric. "O esporte como um domínio masculino: observações sobre as fontes sociais da identidade masculina e suas transformações". In: DUNNING, Eric. Sociologia do esporte e os processos civilizatórios. São Paulo: Annablume, 2014. p. 233-254.

FERNANDES, Danubia de Andrade. "O gênero negro: apontamentos sobre gênero, feminismo e negritude". Revista Estudos Feministas, Florianópolis, v. 24, n. 3, p. 691-713, set./dez. 2016.

FIGARO, Roseli. "Jornalismos e trabalho de jornalistas: desafios para as novas gerações no século XXI". Revista Parágrafo, São Paulo, v. 2, n. 2, p. 23-37, jul./dez. 2014. Disponível em http:// revistaseletronicas.fiamfaam.br/index.php/recicofi/article/view/231. Acesso em 17/06/2019.

FIGARO, Roseli; NONATO, Claudia. "Novos 'arranjos econômicos' alternativos para a produção jornalística". Contemporânea: Revista de Comunicação e Cultura, Salvador, v. 15, n. 1, p. 47-63, jan./abr. 2017. Disponível em https://portalseer.ufba.br/index.php/contemporaneaposcom/issue/ view/1510. Acesso em 17/06/2019.

GIULIANOITI, Richard. Sociologia do futebol: dimensões históricas e socioculturais do esporte das multidões. São Paulo: Nova Alexandria, 2002.

GOELLNER, Silvana. "Mulheres e futebol no Brasil: entre sombras e visibilidades". Revista Brasileira de Educação Física e Esporte, São Paulo, v. 19, n. 2, p. 143-151, abr./jun. 2005.

GRIFFIN, Pat. "Changing the game: homophobia, sexism and lesbians in sport". In: SCRATON, Sheila; FLINTOFF, Anne (Eds.). Gender and sport: a reader. London: Routledge, 2002. p. 193-208.

HALL, Ann. "How should we theorize gender in the context of sport?" In: MESSNER, Michael; SABO, Donald (Eds.). Sport, men, and the gender order: critical feminist perspectives. London: Human Kinetics, 1990. p. 223-240.

HARGREAVES, Jennifer. Sporting females: critical issues in the history and sociology of women's sports. London: Routledge, 1994.

HERSCOVITZ, Heloiza Golbspan. "Jornalistas de São Paulo: quem são e o que pensam em comparação aos jornalistas americanos e franceses". Revista Brasileira da Ciência da Comunicação, São Paulo, v. 23, n. 2, p. 65-86, jul./dez. 2000. Disponível em http://www.portcom.intercom.org.br/revistas/index.php/ revistaintercom/issue/view/34/showToc. Acesso em 08/07/2019.

HIRATA, Helena. "Gênero, classe e raça: interseccionalidade e consubstancialidade das relações sociais". Tempo Social: Revista de Sociologia da USP, São Paulo, v. 26, n. 1, p. 61-73, jun. 2014.

JORGE, Thais de Mendonça; ADGHIRNI, Zélia Leal. "Brazil: need for national debate on women in journalism". In: BYERLY, Carolin (Ed.). The Palgrave international handbook of women and journalism. New York: Palgrave Macmillan, 2013. p. 211-225.

KIDD, Bruce. "The men's cultural centre: sports and the dynamic of women's oppression/men's repression". In: MESSNER, Michael; SABO, Donald (Eds.). Sport, men, and the gender order: critical feminist perspectives. London: Human Kinetics, 1990. p. 31-44.

LOBO, Elisabeth Souza. "O trabalho como linguagem: o gênero no trabalho". BIB, Rio de Janeiro, $n$. 31, p. 7-16, 1991.

MACKINNON, Catharine. "On exceptionality: women as women in law". In: MACKINNON, Catharine (Ed.). Feminism unmodified: discourses on life and law. Cambridge: Harvard University Press, 1987. p. 70-80.

MAZOTTE, Natália; TOSTE, Mônica (Coords.). Mulheres no jornalismo brasileiro. São Paulo: ABRAJl/ Gênero e Número, 2017. Disponível em https://www.mulheresnojornalismo.org.br/12901_GN_relatorio V4.pdf. Acesso em 17/06/2019. 
MILLER, Phyllis; MILLER, Randy. "The invisible woman: female sports journalist in the workplace". J\&MC Quartely, Columbia, v. 72, n. 4, p. 883-889, 1995.

MOORE, Henrietta L. "Fantasias de poder e fantasias de identidade: gênero, raça e violência". Cadernos Pagu, Campinas, v. 14, p. 13-44, 2000.

NEVES, Magda de Almeida. "Anotações sobre trabalho e gênero". Cadernos de Pesquisa, São Paulo, Fundação Carlos Chagas, v. 43, n. 149, p. 404-421, 2013.

NEVEU, Érik. Sociologia do jornalismo. São Paulo: Edições Loyola, 2006.

RIAL, Carmen. "Ainda um 'ponga un exótico' ou uma mudança efetiva? Participação das mulheres na mídia brasileira na Copa". Cuadernos del Mundial, n. 2, p. 2-3, CLACSO, jun. 2014. Disponível em https://clacso.org.ar/cuadernosdelmundial/. Acesso em 19/01/2018.

ROSS, Karen. "Women at work: journalism as en-gendered practice". Journalism Studies, London, v. 2, n. 4, p 531-544, 2001. Disponível em http://dx.doi.org/10.1080/14616700120086404. Acesso em $08 / 01 / 2018$.

SILVA, Marcia Veiga da. Masculino, o gênero do jornalismo: um estudo sobre modos de produção das notícias. 2010. Mestrado (Programa de Pós-Graduação em Comunicação e Informação, Biblioteconomia e Comunicação) - Universidade Federal do Rio Grande do Sul, Porto Alegre, RS, Brasil.

THEBERGE, Nancy. "Toward a feminist alternative to sport as a male preserve". In: BIRREL, Susan; COLE, Cheryl (Eds.). Women, sport and culture. London: Human Kinetics, 1994. p. 181-192.

THEBERGE, Nancy; CRONK, Alan. "Work routines in newspaper sports departments and coverage of women's sports". In: BIRREL, Susan; COLE, Cheryl (Eds.). Women, sport and culture. London: Human Kinetics, 1994. p. 289-299.

VAN ZOONEN, Liesbet. "One of the girls? The changing gender of journalism". In: CARTER, Cynthia; BRANSTON, Gill; ALLAN, Stuart (Eds.). News, gender and power. London: Routledge, 1998. p. 33-46.

VELHO, Gilberto. Individualismo e cultura: notas para uma Antropologia da sociedade contemporânea. Rio de Janeiro: Jorge Zahar Editor, 2004.

WHANNEL, Garry. "Sport and the media". In: COAKLEY, Jay; DUNNING, Eric (Eds.). Handbook of sports studies. London: Sage, 2006. p. 291-380.

WILLIS, Paul. "Women in sport in ideology". In: BIRREL, Susan; COLE, Cheryl (Eds.). Women, sport, and culture. London: Human Kinetics, 1994. p. 31-46.

Leonardo Turchi Pacheco (leonardo.pacheco@unifal-mg.edu.br) é Professor Associado do Instituto de Ciências Humanas e Letras da Universidade Federal de Alfenas (UNIFAL-MG). Realizou estágio pós-doutoral no PPGI Estudos de Lazer na EEFTTO/Universidade Federal de Minas Gerais (UFMG). Doutor em História Social da Cultura pela UFMG. É integrante do Grupo de Estudos Sobre Futebol e Torcidas (GEFUT).

Silvio Ricardo da Silva (profsrs@ufmg.br) é Professor Titular da Universidade Federal de Minas Gerais, coordenador e docente do Programa de Pós-Graduação Interdisciplinar em Estudos do Lazer da UFMG e coordenador do Grupo de Estudos Sobre Futebol e Torcidas (GEFuT). Doutor em Educação Física pela Universidade Estadual de Campinas. Realizou em 2015 estágio pós-doutoral na Faculdade de Ciências Sociais da Universidade de Valência.

\section{COMO CITAR ESSE ARTIGO DE ACORDO COM AS NORMAS DA REVISTA}

PACHECO, Leonardo Turchi; SILVA, Silvio Ricardo da. "Mulheres e jornalismo esportivo: possibilidades e limitações em um campo masculino". Revista Estudos Feministas, Florianópolis, v. 28, n. 3, e61002, 2020.

\section{CONTRIBUIÇÃO DE AUTORIA}

Leonardo Turchi Pacheco: Realizou as entrevistas e fez as análises, realizou a pesquisa empírica de campo e redigiu o texto final.

Silvio Ricardo da Silva: Colaborou nas análises das entrevistas, supervisionou a pesquisa empírica de campo, redigiu e revisou o texto final. 


\section{FINANCIAMENTO}

Não se aplica.

\section{CONSENTIMENTO DE USO DE IMAGEM}

Não se aplica.

APROVAÇÃO DE COMITÊ DE ÉTICA EM PESQUISA

Aprovado pelo Comitê de ética em pesquisa da Universidade Federal de Alfenas; CAAE: 64053717.5.0000.5142; Número do Parecer: 1.940.394.

\section{CONFLITO DE INTERESSES}

Não se aplica.

\section{LICENÇA DE USO}

Este artigo está licenciado sob a Licença Creative Commons CC-BY International. Com essa licença você pode compartilhar, adaptar, criar para qualquer fim, desde que atribua a autoria da obra.

\section{HISTÓRICO}

Recebido em 10/01/2019

Reapresentado em 11/07/2019

Reapresentado em 12/09/2019

Aprovado em 16/09/2019 